\title{
Echocardiography training for cardiac surgery residents: results of a Canadian needs assessment
}

\author{
Mazin Fatani ${ }^{1,2^{*}}$, Kevin Lachapelle ${ }^{1}$, Farhan Bhanji ${ }^{1}$ and Peter McLeod ${ }^{1}$
}

\begin{abstract}
Background: In assessing an unstable patient post cardiac surgery, echocardiography can be an essential tool as part of this assessment. However, it may be under-utilized for several reasons. We conducted this study to determine the perceived needs and training objectives for echocardiography training for cardiac surgery residents.

Methods: This study was a cross-sectional, stratified national survey of cardiac surgery residents, cardiac surgeons, cardiac surgery program directors and cardiologists, designed to acquire opinions on what type and level of objective-based training in echocardiography is required for cardiac surgery residents. Recruitment of survey subjects was through Fluid Surveys email invitations to 201 physicians. Participants were asked to rate the importance of focused echocardiography training for cardiac surgery residents and also give a grade of importance for 18 training objectives.
\end{abstract}

Results: We received 89 completed surveys. More than $80 \%$ of responders feel that echocardiography training should be required for cardiac surgery residents. Forty seven percent of all responders felt that residents should take an echocardiography course with or without a rotation to train in echocardiography. Thirty five percent felt that current training in most programs, which entails a single rotation in echocardiography, is sufficient. Seven training objectives were identified as important by more than $80 \%$ of participants.

Conclusion: Study participants believe that cardiac surgery residents require echocardiography training. The majority agree that echocardiography training should be informed by the identified 7 training objectives.

\section{Background}

Echocardiography is a non-invasive diagnostic tool that can provide useful information about the function and anatomy of the cardiovascular system. In unstable patients a bedside echocardiogram can guide resuscitative interventions and can be lifesaving [1-4]. Currently, many intensivists and emergentologists are adept at using focused echocardiography as an aid to dealing with challenging clinical scenarios in a timely manner. $\mathrm{Nu}$ merous studies demonstrate high accuracy results of this diagnostic tool when done by non-cardiologists who have undergone brief training [3, 5-7]. Echocardiography can be detrimental to assessment of unstable patients on a cardiac surgery ward, especially in the hands of a trained practicing cardiac surgeons or cardiac

\footnotetext{
* Correspondence: dr.mazin_fatani@yahoo.com

${ }^{1}$ McGill University, Montreal, Canada

${ }^{2} U m m$ Al-Qura University, Makkah, Saudi Arabia
}

surgery residents. Currently, the Royal College of Physicians and Surgeons of Canada specialty requirements for cardiac surgery do not mandate resident training in bedside echocardiography. In most Canadian training programs, cardiac surgery residents do a four-week rotation in an echocardiography laboratory.

Needs assessment is crucial in educational planning as education becomes linked to practice $[8,9]$. Surprisingly, the learning needs for cardiac surgery residents' training in echocardiography have never been assessed. Furthermore, we found no credible literature addressing this issue.

This pan-Canadian survey was designed to acquire a national consensus of opinions regarding the perceived echocardiography training needs of cardiac surgery residents. The target audience included cardiac surgeons, cardiac surgery program directors, cardiologists and cardiac surgery residents. 


\section{Methods}

\section{Study design}

This study was a cross-sectional, purposive sampling, national survey of cardiac surgery residents, cardiac surgeons, cardiac surgery program directors and cardiologist educators. The survey was conducted online using FluidSurveys between March and May 2013. Study participants were recruited via email invitations. Statistical power calculations estimated that 50 subjects per group were needed in order to detect a $30 \%$ difference in opinion with a power of 0.80 between any two groups at 0.05 significance. All 12 Canadian cardiac surgery program directors were included in the survey. The Canadian Society of Cardiac Surgeons provided the current list of 73 cardiac surgery residents who were surveyed. Since the remaining two groups are larger populations we asked each cardiac surgery program director and cardiology program director to provide a list of four surgeons and four echocardiographers respectively. Sixty five cardiac surgeons and 51 cardiologists were enrolled. The survey was anonymous and participants were sent two email reminders two weeks apart. The Institutional Review Board of the Faculty of Medicine at McGill University, Montreal, Canada approved the study.

\section{Measurements}

In the first section of the survey, respondents were asked for demographic data including age, sex, professional role, location of practice and own perceived level of competency in echocardiography. In the second section, we asked respondents to opine whether cardiac surgery residents require training in echocardiography and if so what level of training would be required. The Canadian Society of Echocardiography identifies three levels of training based on minimum training duration and procedural volume. Level one is a minimum of four weeks of training and at least 40 echocardiography studies, level two is a minimum of six training blocks (approximately 6 months) and at least 150 complete transthoracic studies, level three is a one year fellowship [10, 11]. In the survey package participants received these definitions as guides to which level they think the residents should be trained. An echocardiography course was added to these options as another possible mode of training. In the third section of the survey, respondents were asked to rate the importance of 18 objectives by selecting one of four options for each objective (1)"must be included", (2)"should be included", (3) "nice to include" or (4) "should not be included". These 18 training objectives were developed by the authors from reviewing the echocardiography training guidelines of the American and Canadian societies of echocardiography as well as objectives published in studies of focused echocardiography training for non-cardiologists. Two senior cardiologists at McGill University reviewed the list of objectives which was then pilot-tested and revised by a committee consisting of a staff cardiologist, a cardiac surgeon and three senior residents in emergency medicine

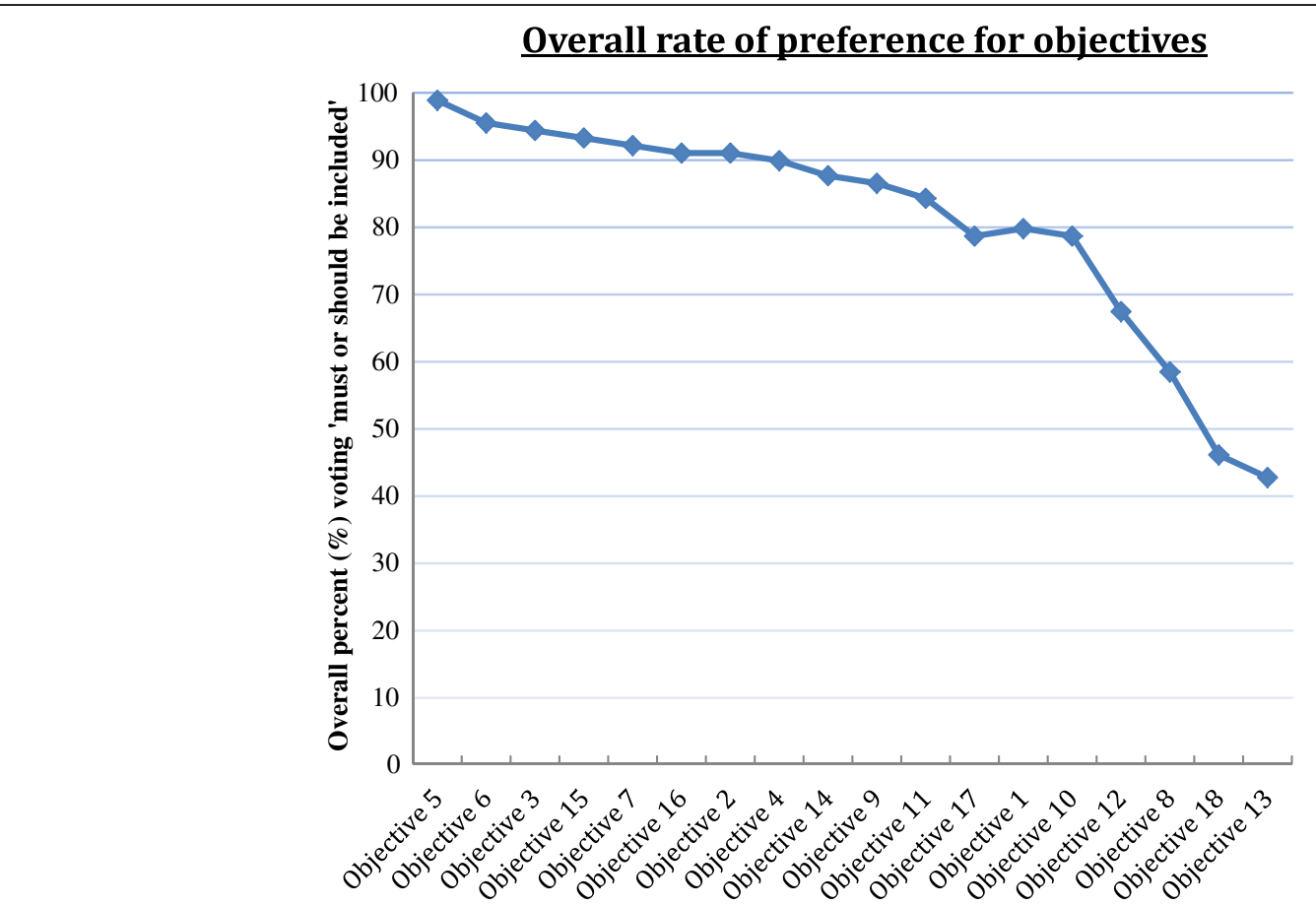

Fig. 1 The Overall percent voting "must or should be included" for each of 18 objectives included in the survey 
and intensive care training. Participants had an opportunity to write additional objectives on the survey instrument if they wished.

\section{Data analysis}

The study population characteristics and responses to all survey questions were characterized using descriptive statistics, including frequency and percentage. For descriptive parsimony, the five response categories for each of the 18 objectives were collapsed into three: 'must be included' or 'should be included'='must or should be included', 'nice to include' or 'unanswered'=neutral, 'should not be included' = should not be included. Based on a natural change in the slope of the line representing the distribution of overall votes for'must or should be included' ordered from highest to lowest preferred objective at about $80 \%$, objectives that had an overall votes of $80 \%$ or more for 'must or should be included' were classified as having achieved a substantial agreement (Fig. 1). We compared physician groups using chi-square and when appropriate (for smaller samples) Fisher's exact tests for independence. Physician group comparisons included cardiac surgeons and directors combined compared to either residents or cardiologists or a specific physician group compared to everybody else for selecting a specific response such as 'must or should be included'. All $P$-values are for two-tailed tests with statistical significance defined as $P \leq 0.05$. SAS software (SAS version 9.3, SAS Institute, Inc., Cary, North Carolina) was used for all analyses.

\section{Results}

Of the 201 surveys sent, 89 were completed (Table 1). Residents and program directors had a similar response rate of 50 and $52 \%$, respectively. Cardiac surgeons had a slightly lower response rate of $46 \%$. Cardiologists were the most underrepresented group with a response rate of $29 \%$. Nevertheless we were able to detect differences in opinion between cardiologists and other respondents. Cardiac surgery residents accounted for $42.7 \%$ of respondents. Cardiac surgeons accounted for $33.7 \%$; cardiologists accounted for $16.9 \%$ and cardiac surgery program directors represented $6.7 \%$ of the overall study sample respondents (Table 2). Respondents from Eastern

Table 1 Survey rate of response by group of participants

\begin{tabular}{lllc}
\hline & Sent & Returned & Response rate (\%) \\
\hline Overall & 201 & 89 & 44.3 \\
Cardiac surgery resident & 73 & 38 & 52.1 \\
Cardiac surgeon & 65 & 30 & 46.2 \\
Cardiologist & 51 & 15 & 29.4 \\
Cardiac surgery program director & 12 & 6 & 50.0 \\
\hline
\end{tabular}

Table 2 Characteristics of respondents $(N=89)$

\begin{tabular}{|c|c|c|}
\hline Characteristic & $\mathrm{N}$ & $\%$ \\
\hline \multicolumn{3}{|l|}{ Professional Role } \\
\hline Cardiac surgery resident & 38 & 42.7 \\
\hline Cardiac surgeon & 30 & 33.7 \\
\hline Cardiologist & 15 & 16.9 \\
\hline Cardiac surgery program director & 6 & 6.7 \\
\hline \multicolumn{3}{|l|}{ Location } \\
\hline Eastern Canada & 33 & 37.1 \\
\hline Western Canada & 28 & 31.5 \\
\hline Central Canada & 26 & 29.2 \\
\hline Unspecified & 2 & 2.3 \\
\hline \multicolumn{3}{|l|}{ Age } \\
\hline$<25$ & 2 & 2.3 \\
\hline $26-35$ & 41 & 46.1 \\
\hline $36-45$ & 17 & 19.1 \\
\hline$>45$ & 29 & 32.6 \\
\hline \multicolumn{3}{|l|}{ Gender } \\
\hline Male & 78 & 87.6 \\
\hline Female & 10 & 11.2 \\
\hline Unspecified & 1 & 1.1 \\
\hline \multicolumn{3}{|c|}{ Self-rated level of competency with Echocardiography } \\
\hline $1-3$ (low) & 19 & 21.4 \\
\hline 4-6 (intermediate) & 30 & 33.7 \\
\hline 7-10 (high) & 37 & 41.6 \\
\hline Unspecified & 3 & 3.4 \\
\hline \multicolumn{3}{|c|}{ Important aspects of respondent's echocardiography training } \\
\hline N/A & 28 & 31.5 \\
\hline Echo course & 6 & 6.7 \\
\hline Echo course and Level 1 & 10 & 11.2 \\
\hline Level 1 & 26 & 29.2 \\
\hline Level 2 & 6 & 6.7 \\
\hline Level 3 & 13 & 14.6 \\
\hline \multicolumn{3}{|c|}{ Current residents' echocardiography training in respondent's program } \\
\hline Don't know & 16 & 18.0 \\
\hline 1 rotation & 51 & 57.3 \\
\hline$>1$ rotation & 10 & 11.2 \\
\hline Other & 12 & 13.5 \\
\hline
\end{tabular}

Canada accounted for $37.1 \%$ of the study sample, while respondents from Western and Central Canada accounted for 31.5 and $29.2 \%$, respectively. Eighty eight percent of respondents were male. The majority were between 26 and 35 years of age and all reported a "variable" self-rated level of competency in echocardiography. Ninety two percent of responders indicated that echocardiography training should be required for cardiac 


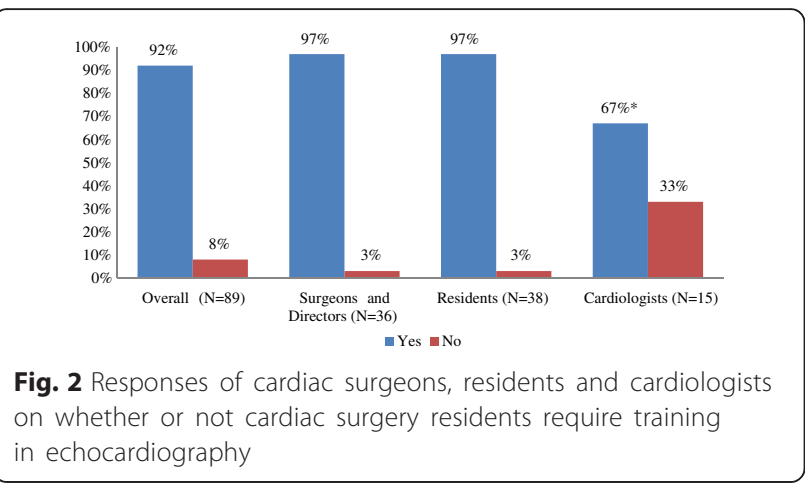

surgery residents. Cardiologists, the group of specialists who were in the lowest response rate group were less enthusiastic about advocating echocardiography training for cardiac surgery residents with only $67 \%$ of the responding cardiologists agreeing that cardiac surgery residents need training in echocardiography. In stark contrast, $97 \%$ of residents and $97 \%$ of surgeons and program directors advocate for echocardiographic training for cardiac surgery residents $(P<0.05)$ (Fig. 2). Overall, $29 \%$ of all responders felt that echo course alone is sufficient while $18 \%$ thought that an echo course along with a one-month rotation are needed (Fig. 3). Therefore $47 \%$ of all responders felt that residents should take an echo course with or without a rotation to train in echocardiography with the majority in each of the 3 groups preferring this choice against other options (Fig. 4). However, another $35 \%$ of all responders thought that current training in most programs, which is level one training, is sufficient. Overall, $79 \%$ of respondents felt that the residents should be trained in both transthoracic and transesophageal echo (Fig. 5). Forty percent of cardiologists and over $80 \%$ of participants in each of the other groups thought that training should be in both transthoracic and transesophageal echo $(P=0.0003)$. Another $40 \%$ of cardiologists suggested that training should be in transthoracic echo only and when compared to surgeons and directors using power calculations the

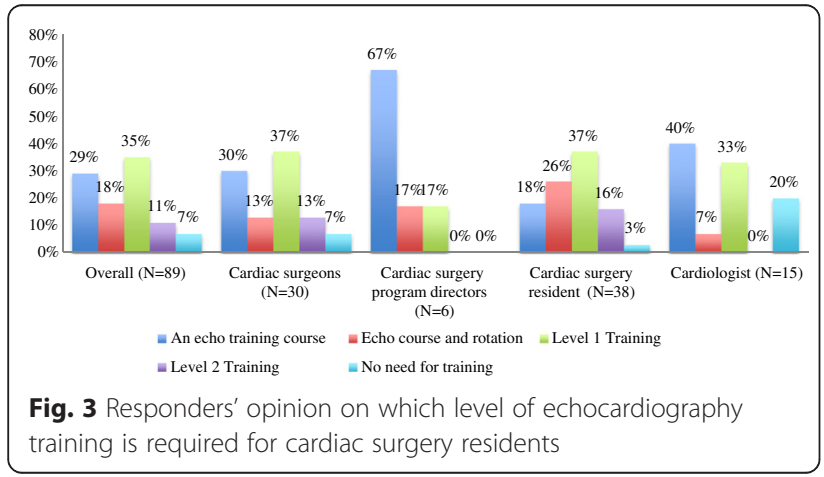

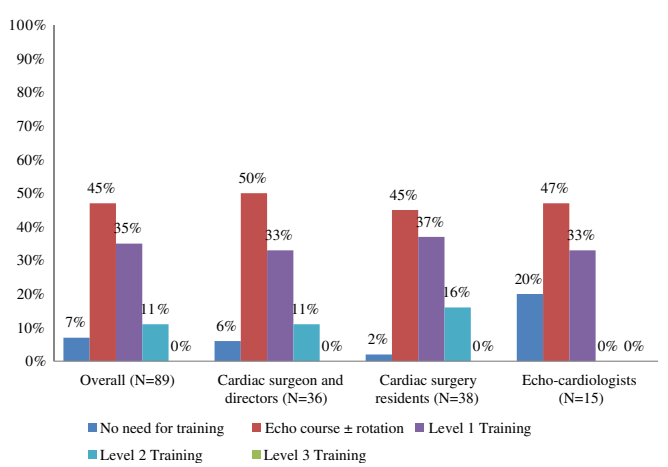

Fig. 4 The majority in each of the 3 groups considered an echo course with or without a rotation to train echocardiography

difference was statistically significant $(P=0.004)$. Based on the survey responses, we classified the 18 training objectives into 3 categories: (1) objectives with substantial agreement among the entire sample ( $\geq 80 \%$ of every group agreed that the objective is important), (2) objectives with strong agreement regarding importance $(\geq 80 \%)$ among residents, surgeons and directors but less agreement $(<80 \%)$ among cardiologists and (3) objectives with broad response variation among the entire sample (i.e. large percentages selecting 'must or should be included', 'neutral', 'should not be included'). Objectives rated as 'should or must be included' by $80 \%$ and more of all participants are (Table 3): 1) recognition of relevant cardiac anatomy, 2) estimation of the systolic function, 3) knowledge of the indications for focused echocardiography, 4) knowledge of the limitations of focused echocardiography, 5) recognition of relevant focused findings to detect pericardial effusions, 6) recognition of relevant focused findings to detect cardiac tamponade and 7) identification of marked ventricular enlargement. Objectives with strong agreement regarding importance $(\geq 80 \%)$ among residents, surgeons and program directors but less agreement $(<80 \%)$ among cardiologists are (Table 4): assessment of gross wall motion abnormalities, understanding of standard ultrasound windows/planes necessary to perform focused echocardiography, recognition of presence of acute

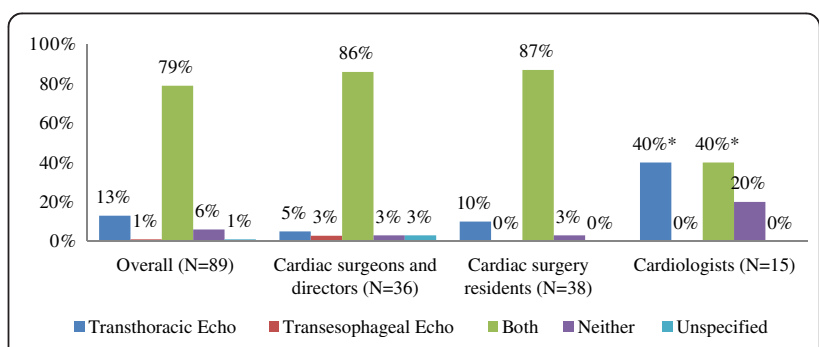

Fig. 5 Responses on whether cardiac surgery residents should be trained in preforming transthoracic or transesophageal echo or both 
Table 3 Objectives rated as 'must or should be included' by more than $80 \%$ overall

\begin{tabular}{|c|c|c|c|c|c|c|c|c|}
\hline \multirow[t]{3}{*}{ Training objectives } & & & \multicolumn{6}{|c|}{ Professional Role } \\
\hline & \multicolumn{2}{|c|}{ Overall } & \multicolumn{2}{|c|}{$\begin{array}{l}\text { Cardiac surgery } \\
\text { residents }(N=38)\end{array}$} & \multicolumn{2}{|c|}{$\begin{array}{l}\text { Cardiologists } \\
(N=15)\end{array}$} & \multicolumn{2}{|c|}{$\begin{array}{l}\text { Cardiac surgery directors } \\
\text { and surgeons }(N=36)\end{array}$} \\
\hline & N & $\%$ & N & $\%$ & $\mathrm{~N}$ & $\%$ & $\mathrm{~N}$ & $\%$ \\
\hline $\begin{array}{l}\text { Recognition of relevant cardiac anatomy including } \\
\text { cardiac chambers, valves, pericardium, and aorta }\end{array}$ & 88 & 98.9 & 38 & 100.0 & 14 & 93.3 & 36 & 100.0 \\
\hline Estimation of the systolic function & 85 & 95.5 & 37 & 97.4 & 12 & 80.0 & 36 & 100.0 \\
\hline Knowledge of the limitations of focused echocardiography & 84 & 94.4 & 37 & 97.4 & 12 & 80.0 & 35 & 97.2 \\
\hline Recognition of relevant focused findings to detect pericardial effusions & 83 & 93.3 & 37 & 97.4 & 13 & 86.7 & 33 & 91.7 \\
\hline Knowledge of the indications for focused echocardiography & 81 & 91.0 & 35 & 92.1 & 12 & 80.0 & 34 & 94.4 \\
\hline Recognition of relevant focused findings to detect cardiac tamponade & 81 & 91.0 & 36 & 94.7 & 12 & 80.0 & 33 & 91.7 \\
\hline Identification of marked ventricular enlargement & 77 & 86.5 & 33 & 86.8 & 12 & 80.0 & 32 & 88.9 \\
\hline
\end{tabular}

valvular regurgitation, recognition of presence of an aortic dissection, recognition of presence of mediastinal clots and knowledge of ultrasound/echo basics. Objectives with broad variation among participants regarding inclusion are listed in Table 5.

\section{Discussion}

The results of this survey indicate that there is a substantial agreement amongst cardiac surgeons, program directors and residents that cardiac surgery residents require echocardiography training. On the other hand cardiologists appear to be significantly less enthusiastic with respect to the desirability of echocardiography training for cardiac surgery residents. One third of the responding cardiologists are of the opinion that cardiac surgery residents do not require training in echocardiography. Despite the fact that cardiologists were underrepresented in the survey, power calculations indicate that this difference in opinions was statistically significant.

Survey participants were asked their opinions on the level of echocardiography training required for cardiac surgery residents. The majority of responders in each group thought that an echo course with or without a rotation in echocardiography is desirable. Others thought that level one training alone is sufficient and none of the participants thought level three is required. Very few considered a level two training as necessary.

From the selection of 18 objectives 7 were identified as 'must or should be included' by the majority of participants. The authors feel that any echocardiographytraining curriculum for cardiac surgery residents should include these seven objectives. Six other objectives were rated as important by the surgeons and the residents but were not rated as important by the cardiologists. Surgeons may have considered those objectives as mostly related to their practical needs where cardiologists may think that some of these objectives are technically more difficult to acquire during a brief period of training.

\section{Conclusion}

We conclude that there is a need for echocardiography training for cardiac surgery residents. An echocardiography

Table 4 Objectives rated as 'must or should be included' by more than $80 \%$ of all residents, surgeons and directors but not cardiologists

\begin{tabular}{|c|c|c|c|c|c|c|c|c|}
\hline \multirow[t]{3}{*}{ Training objectives } & & & \multicolumn{6}{|c|}{ Professional Role } \\
\hline & \multicolumn{2}{|c|}{ Overall } & \multicolumn{2}{|c|}{$\begin{array}{l}\text { Cardiac surgery } \\
\text { residents }(N=38)\end{array}$} & \multicolumn{2}{|c|}{$\begin{array}{l}\text { Cardiologists } \\
(N=15)\end{array}$} & \multicolumn{2}{|c|}{$\begin{array}{l}\text { Cardiac surgery directors } \\
\text { and surgeons }(N=36)\end{array}$} \\
\hline & $\mathrm{N}$ & $\%$ & $\mathrm{~N}$ & $\%$ & $\mathrm{~N}$ & $\%$ & $\mathrm{~N}$ & $\%$ \\
\hline Assessment of gross wall motion abnormalities & 82 & 92.1 & 35 & 92.1 & 11 & 73.3 & 36 & 100.0 \\
\hline $\begin{array}{l}\text { Understanding of standard ultrasound windows/planes } \\
\text { necessary to perform focused echocardiography }\end{array}$ & 80 & 89.9 & 37 & 97.4 & 11 & 73.3 & 32 & 88.9 \\
\hline Recognition of presence of acute valvular regurgitation & 78 & 87.6 & 36 & 94.7 & 11 & 73.3 & 31 & 86.1 \\
\hline Recognition of presence of an aortic dissection & 75 & 84.3 & 32 & 84.2 & 11 & 73.3 & 32 & 88.9 \\
\hline Recognition of presence of mediastinal clots & 71 & 79.8 & 31 & 81.6 & 9 & $60^{*}$ & 31 & 86.1 \\
\hline Knowledge of ultrasound/echo basics & 70 & 78.7 & 32 & 84.2 & 7 & $46.67^{*}$ & 31 & 86.1 \\
\hline
\end{tabular}

${ }^{*} P<0.05$ for comparisons between cardiac surgeons and directors vs. cardiologists. All $p$-values were from two-tailed Fisher's Exact Test 
Table 5 Objectives with broad variation among participants regarding inclusion

\begin{tabular}{|c|c|c|c|c|c|c|c|c|}
\hline \multirow[t]{3}{*}{ Training objectives } & \multirow{2}{*}{\multicolumn{2}{|c|}{ Overall }} & \multicolumn{6}{|c|}{ Professional Role } \\
\hline & & & \multicolumn{2}{|c|}{$\begin{array}{l}\text { Cardiac surgery } \\
\text { residents }(N=38)\end{array}$} & \multicolumn{2}{|c|}{$\begin{array}{l}\text { Cardiologists } \\
(N=15)\end{array}$} & \multicolumn{2}{|c|}{$\begin{array}{l}\text { Cardiac surgery directors } \\
\text { and surgeons }(N=36)\end{array}$} \\
\hline & $\mathrm{N}$ & $\%$ & $\mathrm{~N}$ & $\%$ & $\mathrm{~N}$ & $\%$ & $\mathrm{~N}$ & $\%$ \\
\hline $\begin{array}{l}\text { Recognition of dilated aortic root and/or } \\
\text { thoracic aorta }\end{array}$ & 70 & 78.7 & 29 & 76.3 & 11 & 73.3 & 30 & 83.3 \\
\hline Use of echo guidance for pericardiocentesis & 60 & 67.4 & 26 & 68.4 & 9 & 60.0 & 25 & 69.4 \\
\hline $\begin{array}{l}\text { Estimation of right atrial pressure through } \\
\text { examination of inferior vena caval compliance }\end{array}$ & 52 & 58.4 & 26 & $68.42^{*}$ & 8 & 53.3 & 18 & 50.0 \\
\hline Techniques to estimate pulmonary artery pressure & 41 & 46.1 & 20 & 52.6 & 7 & 46.7 & 14 & 38.9 \\
\hline Confirmation of transvenous pacing wire placement & 38 & 42.7 & 19 & 50.0 & 6 & 40.0 & 13 & 36.1 \\
\hline
\end{tabular}

${ }^{*} P<0.05$ for all comparisons (cardiac surgeons and directors vs. either residents or cardiologists). All $p$-values were from two-tailed Fisher's Exact Test

course directed to the learning needs of the residents in performing a focused echocardiography exam should be considered. We anticipate that all residents in cardiac surgery will soon be competent to perform focused echocardiography exams on unstable patients. Focused echocardiography exams should not replace clinical judgment, the physical exam and expert echocardiography. In emergency situations residents and cardiac surgeons should be capable of performing and interpreting satisfactory echocardiogram on their patients. This study can serve as a starting point to develop an echocardiography-training curriculum for cardiac surgery residents.

\section{Authors' contributions}

MF did the literature review, constructed the survey questionnaire, sent out the email invitations and reminders, collected the data and wrote of the manuscript. $\mathrm{KL}$ identified the need for the study, helped with the study design, review of the collected data and helped with the figures and the writing of the manuscript. FB helped with the study design, literature review, data collection and analysis and review of the manuscript. PM assisted in constructing the survey questionnaire, review of the data as well as writing of the manuscript. All authors read and approved the final manuscript.

\section{Competing interests}

The authors declare that they have no competing interests.

Received: 21 September 2015 Accepted: 14 June 2016

Published online: 13 July 2016

\section{References}

1. Beaulieu Y et al. Bedside echocardiography in the assessment of the critically ill. Crit Care Med. 2007:35:5

2. Schmidlin D, Bernard E, et al. Indications and impact of postoperative transesophageal echocardiography in cardiac surgical patients. Crit Care Med. 2001:29:2143

3. Jones AE et al. Focused Training of Emergency Medicine Residents in Goaldirected Echocardiography: A Prospective Study. Acad Emerg Med. 2003;10:10.

4. Showkathali R et al. Echocardiography and the critically ill patient. Curr Anaesth Crit Care. 2006:17:237.

5. Labovitz AJ, Noble VE, et al. Focused Cardiac Ultrasound in the Emergent Setting: A Consensus Statement of the American Society of Echocardiography and American College of Emergency Physicians. J Am Soc Echocardiograph. 2010;23:1225.

6. Moore CL et al. Determination of Left Ventricular Function by Emergency Physician Echocardiography of Hypotensive Patients. Acad Emerg Med. 2002;9:3.
7. Manasia AR et al. Feasibility and Potential Clinical Utility of Goal-Directed Transthoracic Echocardiography Performed by Noncardiologist Intensivists Using a Small Hand-Carried Device (SonoHeart) in Critically III Patients. J Cardiothorac Vasc Anesth. 2005:19:155.

8. Grant J et al. Learning needs assessment: assessing the need. BMJ. 2002;324:156-9.

9. Ratnapalan S, Hilliard R. Needs Assessment in Postgraduate Medical Education: A Review. Med Educ Online. 2002;7:8.

10. Position Statement and Recommendations of the Canadian Society of Echocardiography Consensus Panel. 2010 CCS/CSE Guidelines for Physician Training and Maintenance of Competence in Adult Echocardiography. Can J Cardiol. 2011;27:862.

11. A Report of the American College of Cardiology/American Heart Association/American College of Physicians-American Society of Internal Medicine Task Force on Clinical Competence. ACC/AHA Clinical Competence Statement on Echocardiography. Journal of the American College of Cardiology. 2003:41:1067.

Submit your next manuscript to BioMed Central and we will help you at every step:

- We accept pre-submission inquiries

- Our selector tool helps you to find the most relevant journal

- We provide round the clock customer support

- Convenient online submission

- Thorough peer review

- Inclusion in PubMed and all major indexing services

- Maximum visibility for your research

Submit your manuscript at www.biomedcentral.com/submit 